\title{
Effect of Decadal Kuroshio Extension Jet and Eddy Variability on the Modification of North Pacific Intermediate Water
}

\author{
Bo QIU AND SHUIMING CHEN \\ Department of Oceanography, University of Hawaii at Manoa, Honolulu, Hawaii
}

(Manuscript received 9 September 2010, in final form 22 November 2010)

\begin{abstract}
Salinity modifications in the North Pacific Intermediate Water (NPIW) core layer of 26.7-26.8 $\sigma_{\theta}$ in the western North Pacific Ocean are investigated using temperature-salinity data from available profiling float and hydrographic measurements in 2002-09. During 2002-05, when the Kuroshio Extension (KE) jet was intense and zonally elongated, coherent positive salinity anomalies appeared along the inflow KE jet southeast of Japan and in the downstream Mixed Water region east of $152^{\circ} \mathrm{E}$. Broad-scale negative salinity anomalies were detected south of the KE jet and in the upstream Mixed Water region west of $152^{\circ} \mathrm{E}$. The signs of these observed salinity anomalies were reversed in 2006-09, when the KE jet transitioned to a weakened and zonally contracted dynamic state. By adopting an isopycnal advection-diffusion model and conducting model runs with the time-dependent advective field inferred from the eddy-resolving satellite altimeter sea surface height data, it is found that the observed salinity anomalies are oscillatory in nature and are determined not only by the decadally varying KE jet itself but also by mesoscale eddy signals that modulate temporally and longitudinally along the path of the KE jet.
\end{abstract}

\section{Introduction}

The Kuroshio Extension (KE) is an eastward-flowing inertial jet in the subtropical western North Pacific after the Kuroshio separates from the coast of Japan at $35^{\circ} \mathrm{N}, 140^{\circ} \mathrm{E}$ (Fig. 1). Being the extension of a winddriven western boundary current, the KE has long been recognized as a current system rich in large-amplitude meanders and energetic pinched-off eddies (e.g., Mizuno and White 1983; Qiu et al. 1991; Yasuda et al. 1992, among others). An important feature emerging from the high-quality satellite altimeter measurements of the past 18 years is that the KE current system undergoes clearly defined decadal oscillations between two dynamic states. When the KE jet is in an elongated state, its transport and latitudinal position tend to be greater and more northerly, the southern recirculation gyre tends to strengthen, and the eddy kinetic energy level in the upstream KE region tends to drop (Qiu and Chen 2005; Kelly et al. 2007). The reverse is true when the $\mathrm{KE}$ jet changes to a contracted state. Since October 1992, after the satellite altimeter

Corresponding author address: Dr. Bo Qiu, Department of Oceanography, University of Hawaii at Manoa, 1000 Pope Road, Honolulu, HI 96822.

E-mail: bo@soest.hawaii.edu measurements became available, the contracted state of the KE jet appeared in 1995-2001 and in 2006-09 and the elongated state was detected in the remaining intervening years.

The cause responsible for the transitions between the elongated and contracted states of the KE jet has been explored extensively both observationally and based on eddy-resolving ocean general circulation model (OGCM) simulations. It is by now relatively well established that the observed transitions were initiated by the decadally fluctuating wind stress curl forcing over the central midlatitude North Pacific Ocean (e.g., Miller et al. 1998; Deser et al. 1999; Seager et al. 2001; Qiu 2003; Taguchi et al. 2005, 2007; Qiu et al. 2007; Ceballos et al. 2009). Specifically, when the central North Pacific wind stress curl anomalies are positive, enhanced Ekman flux divergence generates negative local sea surface height ( $\mathrm{SSH}$ ) anomalies. As these wind-induced negative $\mathrm{SSH}$ anomalies propagate westward into the KE region after a delay of 3-4 yr, they weaken the zonal KE jet, leading to a contracted state of the KE system with a reduced recirculation gyre and an active eddy kinetic energy field. The negative wind stress curl anomaly forcing in the central North Pacific, on the other hand, generates positive SSH anomalies that lead to the elongated state of the KE jet. Compared with the wind-induced dynamic state 


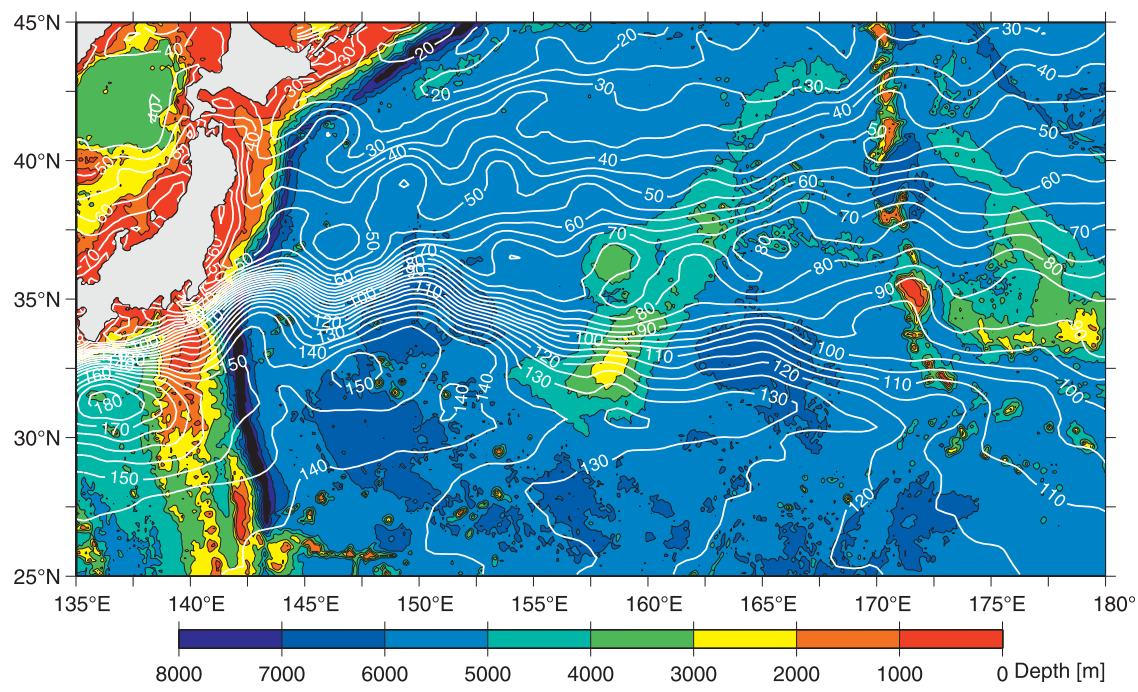

FIG. 1. Mean sea surface height field (cm, white contours) of the western North Pacific Ocean from Rio et al. (2009) for the period of 1992-2009. Colored map shows the bathymetry based on Smith and Sandwell (1994).

transitions, the role played by the nonlinear mesoscale eddies in determining the amplitude of the KE jet migration and the strength of the recirculation gyre is yet to be fully quantified (Berloff et al. 2007; Taguchi et al. 2007; Pierini et al. 2009; Qiu and Chen 2010; Nakano and Ishikawa 2010).

Decadal modulations in the KE's dynamic state can exert a significant impact on regional water mass formation and transformation processes. Using available hydrographic and profiling float temperature-salinity $(T-S)$ data, several recent studies have examined this impact in connection with the Subtropical Mode Water (STMW) formation south of the KE jet. During the contracted state of the KE system, for example, Qiu and Chen (2006) show that the elevated eddy variability brings upperocean high potential vorticity (PV) water of the Mixed Water region southward, creating a stratified upper-ocean condition in the recirculation gyre region unfavorable for the wintertime deep convection and STMW formation. Because the eddy-induced PV exchange occurs on the intraannual time scale, the effect on STMW formation by the KE dynamic state is observed to be highly effective (Qiu et al. 2007).

During its contracted state, the permanent thermocline depth south of the KE jet becomes shallower and this can also contribute to an enhanced upper-ocean stratification and lead to reduced STMW formation (Sugimoto and Hanawa 2010). Although the shoaled permanent thermocline (or, equivalently, the negative SSH) is initiated by the wind forcing in the central North Pacific as we reviewed above, it is worth emphasizing that the windinduced, negative SSH anomalies alone are insufficient to explain the observed permanent thermocline depth (or $\mathrm{SSH}$ ) changes in the recirculation gyre (see Taguchi et al. 2007; Qiu and Chen 2010). Contribution from the feedback of nonlinear eddies is required to fully explain the observed upper-ocean stratification changes between the different dynamic states of the KE jet. Changes in the KE's dynamic state are not only important for the formation of STMW but also its subsequent evolutions. While it tends to remain trapped within the recirculation gyre during the elongated state of the KE jet, STMW tends to be carried away from its formation region during the KE's contracted state (Oka 2009; Oka et al. 2011).

Another important water mass existing in the North Pacific Ocean is the North Pacific Intermediate Water (NPIW) characterized by a salinity minimum on the 26.7-26.8 $\sigma_{\theta}$ surface (Reid 1965; Talley 1993; Qiu 1995; Yasuda et al. 1996). NPIW is formed in the "Mixed Water" region (also known as the Kuroshio-Oyashio interfrontal zone) north of the KE jet where the subarcticorigin cold and fresh Oyashio water mixes with the warm and saline KE water of subtropical origin. Many previous studies of NPIW have focused on its formation processes. For example, Talley (1991) explored the freshening processes to the $26.8 \sigma_{\theta}$ surface in the Okhotsk Sea through brine rejection below sea ice formation. Although mixing within the broad Mixed Water region was shown by Talley (1997) to be important for the NPIW formation, Yasuda et al. (1996) emphasized the primary site for NPIW formation was located along the northern periphery of the meandering KE (see also Yasuda 1997). In addition to the ventilation in the western North Pacific, negative buoyancy fluxes and wind 
stirring caused by severe winter conditions in the Alaskan gyre have also been identified as playing a role in transferring the fresh surface water to the NPIW density surface (Van Scoy et al. 1991; You et al. 2000). For a comprehensive review of the advancement in our understanding of the NPIW formation, the readers are referred to Yasuda (2004).

Because NPIW is formed adjacent to the KE jet and because a significant portion of the newly formed NPIW crosses the KE jet to spread into the interior subtropical circulation, it is natural to ask to what extend the decadally modulating KE dynamic state can bring about the property modifications to NPIW. In comparison to the exploration of STMW variability, it is more challenging to investigate the NPIW changes because far less in situ salinity measurements exist than for temperature in both space and time. Indeed, previous studies on the NPIW variability in the $\mathrm{KE}$ region are limited to the repeat hydrographic section along $165^{\circ} \mathrm{E}$ (e.g., Kouketsu et al. 2007). This lack of salinity data, however, changed after 2001 thanks to the establishment of the International Argo Program (Roemmich et al. 2009). In the KE region of interest to this study, the number of profiling float $T-S$ data is further increased with the addition of 48 floats deployed in 2004 and 2005 as part of the Kuroshio Extension System Study (KESS) project (available online at http://www.uskess.org; Qiu et al. 2007).

The present study has three objectives. The first is to provide an update on the time-varying dynamic state of the KE system. In particular, we will emphasize the outof-phase fluctuations in the eddy kinetic energy level between the upstream versus downstream KE regions. Although previously undocumented, this feature of longitudinally varying eddy variability plays an important role in determining the time-varying salinity signals detected in the NPIW layer. The second objective is to examine the salinity changes on the 26.7-26.8 $\sigma_{\theta}$ surface through analysis of $T-S$ data from the Argo and KESS profiling floats, as well as from other in situ conductivitytemperature-depth (CTD) measurements. Our third objective is to clarify the connection between the observed NPIW salinity changes and the decadal modulations of the KE dynamic state. Quantification of this connection is pursued by adopting an isopycnal advection-diffusion model whose time-dependent advective field is specified by the eddy-resolving satellite altimeter SSH data.

\section{Decadally modulating KE dynamic state}

To examine the changes in the KE dynamic state, we use the global SSH anomaly dataset compiled by the Collocte Localisation Satellites (CLS) Space Oceanographic Division of Toulouse, France. This dataset

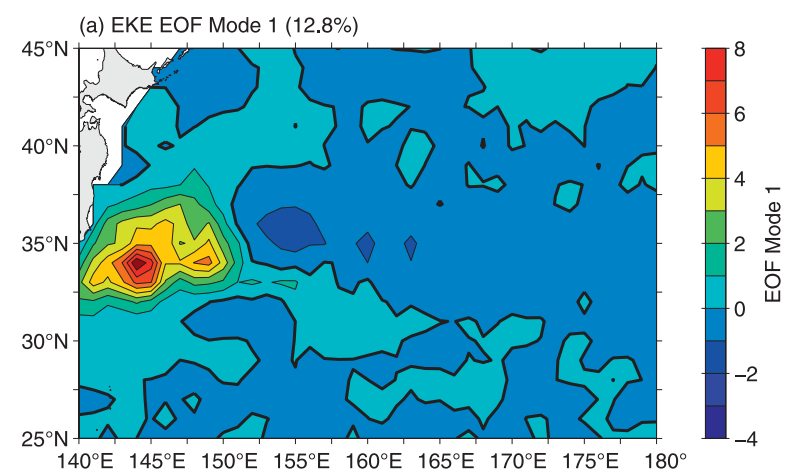

(b) Mode 1 Timeseries

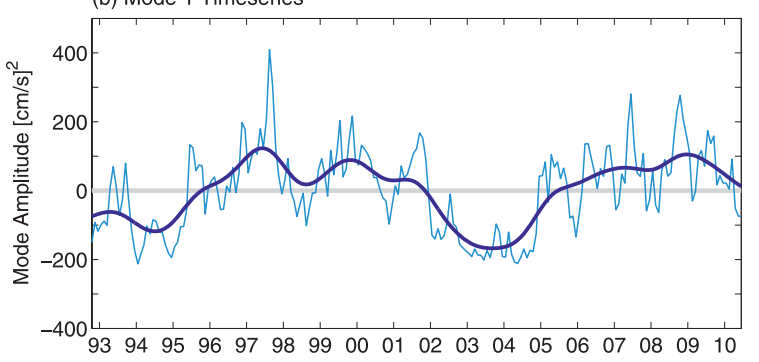

FIG. 2. First EOF mode of the SSH-derived eddy kinetic energy in the western North Pacific Ocean: (a) the spatial pattern and (b) the corresponding weighting function. The mode explains $12.8 \%$ of the total EKE variance.

merges along-track SSH measurements from all satellite altimeter missions after October 1992 and has a 7-day temporal resolution and a $1 / 3^{\circ}$-longitude Mercator spatial resolution (Ducet et al. 2000). By adding the hybrid mean SSH field $\bar{h}(x, y)$ of Rio et al. (2009; see Fig. 1) to the SSH anomaly field $h^{\prime}(x, y, t)$, we obtain the total SSH field: $h=\bar{h}+h^{\prime}$. For brevity, the total SSH field will be referred to simply as the SSH field throughout this study.

One effective way to capture the low-frequency eddy variability of the KE system is to conduct an empirical orthogonal function (EOF) analysis of the eddy kinetic energy field, where eddy kinetic energy is calculated using the SSH anomaly data ${ }^{1}$ through geostrophy,

$$
\mathrm{EKE}=\frac{1}{2}\left[\left(\frac{g}{f} \frac{\partial h^{\prime}}{\partial x}\right)^{2}+\left(\frac{g}{f} \frac{\partial h^{\prime}}{\partial y}\right)^{2}\right],
$$

where $g$ is the gravity constant and $f$ the Coriolis parameter. Figure 2 shows the spatial pattern and weighting coefficient of the first EOF mode, explaining $12.8 \%$ of the total EKE variance. The weighting coefficient of the mode is dominated by decadal modulations in

\footnotetext{
${ }^{1}$ To emphasize the contribution from the mesoscale eddy signals, the $h^{\prime}$ data used in Eq. (1) is high-pass filtered with time scales shorter than 300 days.
} 
which high (low) EKE level is observed in 1996-2001 and 2006-09 (1993-95 and 2002-05). A comparison between the spatial EOF pattern of Fig. 2a and Fig. 1 reveals that the elevated EKE band closely follows the mean path of the KE jet, a result not unexpected because it is the baroclinicity of the KE jet that supplies the energy source for the enhanced eddy activity.

What is surprising from Fig. $2 \mathrm{a}$ is that the decadally modulating eddy activities have opposite signs in the upstream versus downstream KE regions. In other words, when the mesoscale eddy variability was enhanced in 1996-2001 and 2006-09 in the upstream region west of $152^{\circ} \mathrm{E}$, the downstream EKE level east of $152^{\circ} \mathrm{E}$ was in fact reduced. This out-of-phase relationship between the upstream and downstream eddy activity levels can also be verified if we compare the EKE time series averaged in the upstream and downstream KE regions as shown in Figs. 3a,b. The linear correlation coefficient between these two EKE time series is $r=-0.56$.

This longitudinal EKE variation along the KE path is related to the intensity changes in the KE jet and its southern recirculation gyre. To illustrate this point, we contrast in Fig. 4 the yearly averaged EKE and SSH maps in 2004 versus 2008. Here, 2004 and 2008 are chosen to represent the low and high EKE state in the upstream KE region, respectively. Compared to 2008, Fig. 4a shows that the KE jet in 2004 was more intense (i.e., having a greater cross-stream SSH jump), extended more coherently eastward of $152^{\circ} \mathrm{E}$, and was accompanied by the presence of a better defined southern recirculation gyre. The reduced EKE level in the upstream KE region in 2004 is due to the strengthened recirculation gyre that stabilizes the upstream KE jet (Fig. 4c). In the downstream region east of $152^{\circ} \mathrm{E}$, on the other hand, the enhanced eddy activity is likely a result of interaction by the zonally extended and strengthened KE jet with the underlying Shatsky Rise along $\sim 158^{\circ} \mathrm{E}$ (see Fig. 1).

To quantify the connection between the time-varying EKE signals and the strength of the KE jet, we define the KE axis by the 100-cm SSH contours and plot in Fig. $3 \mathrm{c}$ the time series of SSH difference $\langle\delta h\rangle$ across the KE jet averaged from $140^{\circ} \mathrm{E}$ to $165^{\circ} \mathrm{E}$. Here $\delta h$ is evaluated at each longitude by first averaging the SSH values over the $1.5^{\circ}$ bins centered $1^{\circ}$ north and south of the KE's axis $\left(h_{N}\right.$ and $\left.h_{S}\right)$ and then taking the difference $\delta h=h_{S}-h_{N}$. Consistent with the scenario inferred from Fig. 4, a favorable correspondence exists between a zonally strengthened KE jet and a reduced (enhanced) eddy activity in the upstream (downstream) KE region. ${ }^{2}$ Notice that the

\footnotetext{
${ }^{2}$ The linear correlation coefficients between Figs. $3 \mathrm{c}$ and $3 \mathrm{a}$ and between Figs. $3 \mathrm{c}$ and $3 \mathrm{~b}$ are $r=-0.56$ and 0.80 , respectively.
}
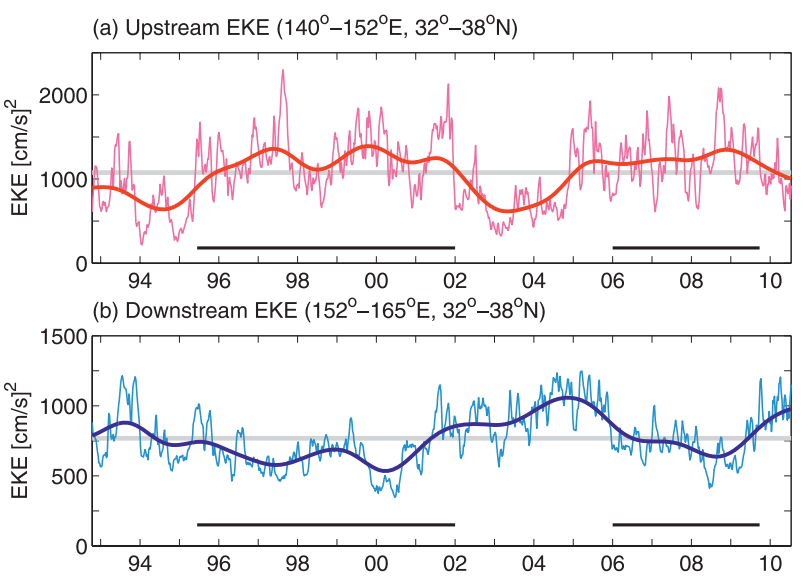

(c) KE Strength $\left(140^{\circ}-165^{\circ} \mathrm{E}\right)$
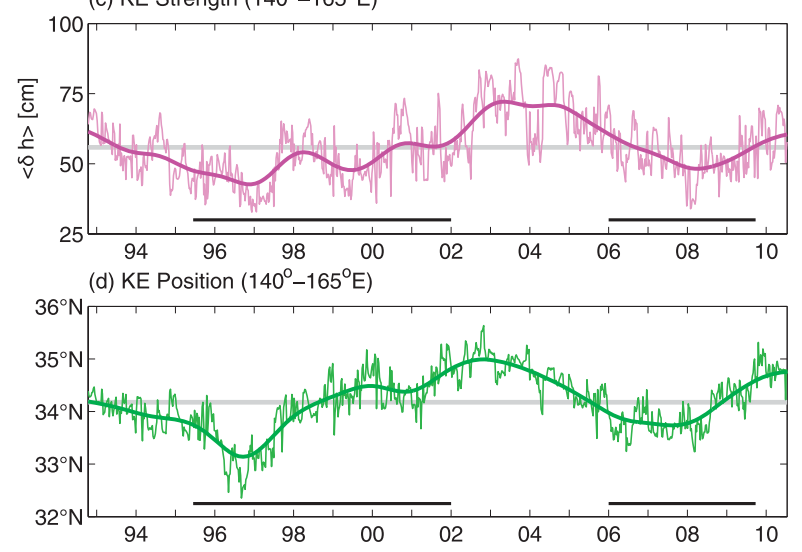

FIG. 3. (a) Time series of eddy kinetic energy in the upstream $\mathrm{KE}$ region of $32^{\circ}-38^{\circ} \mathrm{N}, 140^{\circ}-152^{\circ} \mathrm{E}$. (b) EKE in the downstream $\mathrm{KE}$ region of $32^{\circ}-38^{\circ} \mathrm{N}, 152^{\circ}-165^{\circ} \mathrm{E}$. (c) SSH difference across the $\mathrm{KE}$ jet averaged from $140^{\circ}$ to $165^{\circ} \mathrm{E}$. (d) Latitudinal position of the $\mathrm{KE}$ jet averaged from $140^{\circ}$ to $165^{\circ} \mathrm{E}$. Dark lines denote the periods when the upstream (downstream) $\mathrm{KE}$ is in the unstable (stable) state.

peak-to-peak $\langle\delta h\rangle$ changes $(35 \mathrm{~cm}$ versus $85 \mathrm{~cm})$ are as large as the time-mean $\langle\delta h\rangle$ value $(55 \mathrm{~cm})$ itself. $\mathrm{Al}-$ though not quantified in this study, it is possible to verify that the decadal strengthening/weakening of the KE jet is in sync with the temporal evolution of the southern recirculation gyre (see Qiu and Chen 2005). In association with the intensity fluctuations of the KE jet, there exists a concurrent change in the latitudinal position of the KE jet. As shown in Fig. 3d, the zonally averaged KE jet position tends to migrate northward when the KE jet intensifies and vice versa (the two time series shown in Figs. 3d,c have a linear correlation coefficient $r=0.75$ ). The peak-to-peak changes in KE position are $\sim 2.5^{\circ}$ in latitude.

It is worth emphasizing that the decadal variability observed in the KE jet and recirculation gyre is not a phenomenon initiated by the local nonlinear ocean dynamics. The strengthening (weakening) of the recirculation 
(a) $\mathrm{SSH}$ in 2004

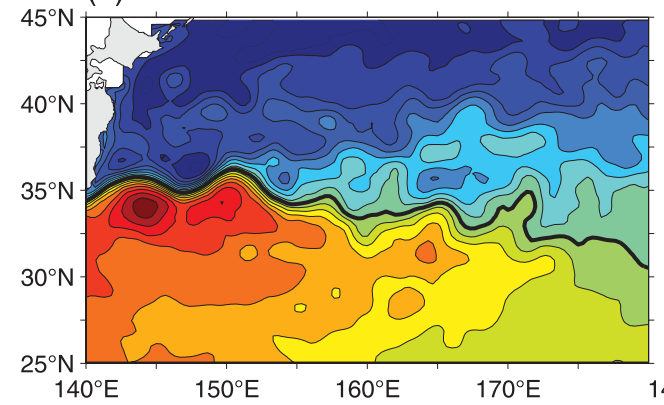

(c) EKE in 2004

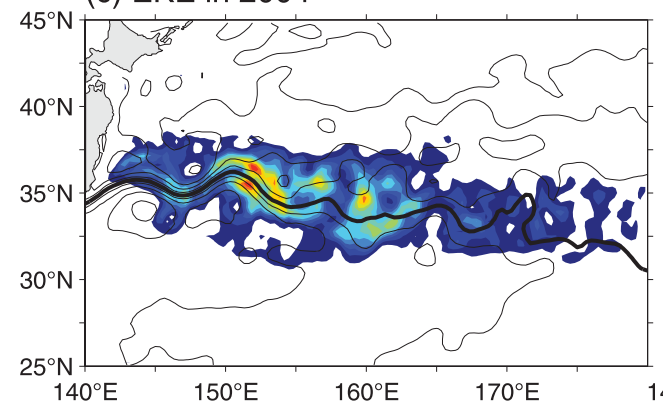

(b) SSH in 2008

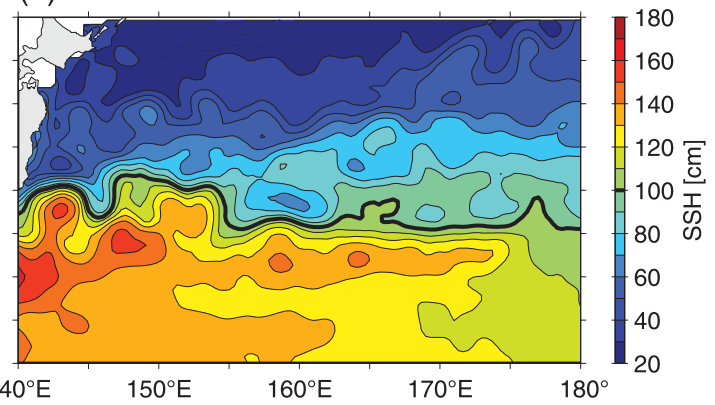

(d) EKE in 2008

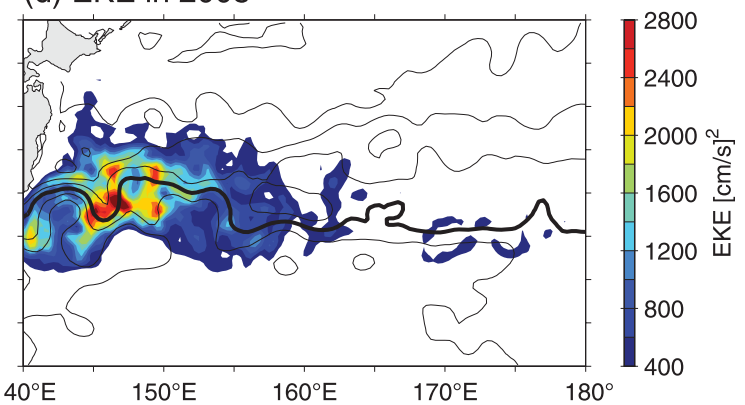

FIG. 4. Annual-mean SSH distributions in (a) 2004 vs (b) 2008. Contour intervals are $5 \mathrm{~cm}$ and the thick black lines denote the 100-cm SSH contours. Distributions of eddy kinetic energy (in color) in (c) 2004 vs (d) 2008. Background contours denote the corresponding SSH field shown in (a),(b).

gyre is connected to the buildup of positive (negative) $\mathrm{SSH}$ anomalies south of the KE jet. As discernible from Fig. 5b, which shows the time-longitude plot of $h^{\prime}(x, y, t)$ averaged in the $32^{\circ}-34^{\circ} \mathrm{N}$ band of the recirculation gyre, the decadally varying $\mathrm{SSH}$ signals corresponding to the $\langle\delta h\rangle$ time series (Fig. 5a) can all be traced back in time to have originated from the central North Pacific Ocean around $160^{\circ} \mathrm{W}$. In fact, a linearized, wind-driven vorticity model can be used to confirm that the observed SSH phase transitions in the recirculation gyre are induced by the wind stress curl variability associated with the Pacific decadal oscillations (PDOs) (Mantua et al. 1997). Specifically, when the PDO index is positive (see Fig. 5c), the Aleutian low intensifies and shifts southward, working to generate negative SSH anomalies near $160^{\circ} \mathrm{W}$ in the eastern North Pacific through Ekman divergence. The opposite is true when the PDO index turns negative: the wind-induced Ekman convergence in this case leads to regional positive SSH anomalies near $160^{\circ} \mathrm{W}$. Once they are generated in the eastern North Pacific Ocean, the SSH anomalies propagate subsequently westward at the speed of baroclinic Rossby waves, $c_{R} \simeq 3.7 \mathrm{~cm} \mathrm{~s}^{-1}$. While the PDO-related wind forcing is responsible for the phase transitions, the nonlinear ocean dynamics is important in determining the amplitude of the SSH signals in the recirculation gyre (Taguchi et al. 2007; Qiu and Chen 2010, and references therein).

\section{Observed NPIW salinity changes}

As we noted in Introduction, the amount of in situ $T-S$ measurements in the western North Pacific Ocean has increased significantly since 2001 as a result of the International Argo Program and the KESS project. For our analysis, we further supplemented the profiling float $T-S$ data with the CTD data archived by the Japan Oceanographic Data Center (available online at http:// www.jodc.go.jp) and from the KESS project (available online at http://www.uskess.org). Figure 6a shows the salinity values within the 26.7-26.8 $\sigma_{\theta}$ layer from individual float and CTD measurements for the period from 2001 to the present. The 37373 available data points cover well the western North Pacific region of our interest, and the salinity distribution after isopycnal interpolation is shown in Fig. 6b. The distribution pattern is not that different from the climatological salinity maps on the $26.8 \sigma_{\theta}$ density surface [e.g., Fig. 6 in Talley (1993) and Fig. 6a in Qiu (1995)]. Broadly speaking, the salinity value is lowest off Hokkaido and the Kuril Islands and increases progressively southward when the newly formed NPIW mixes with the saltier subtropical waters. The highest salinity value in the region of our interest is seen on the inflow KE jet, which brings older and saltier NPIW back to the Mixed Water region. 


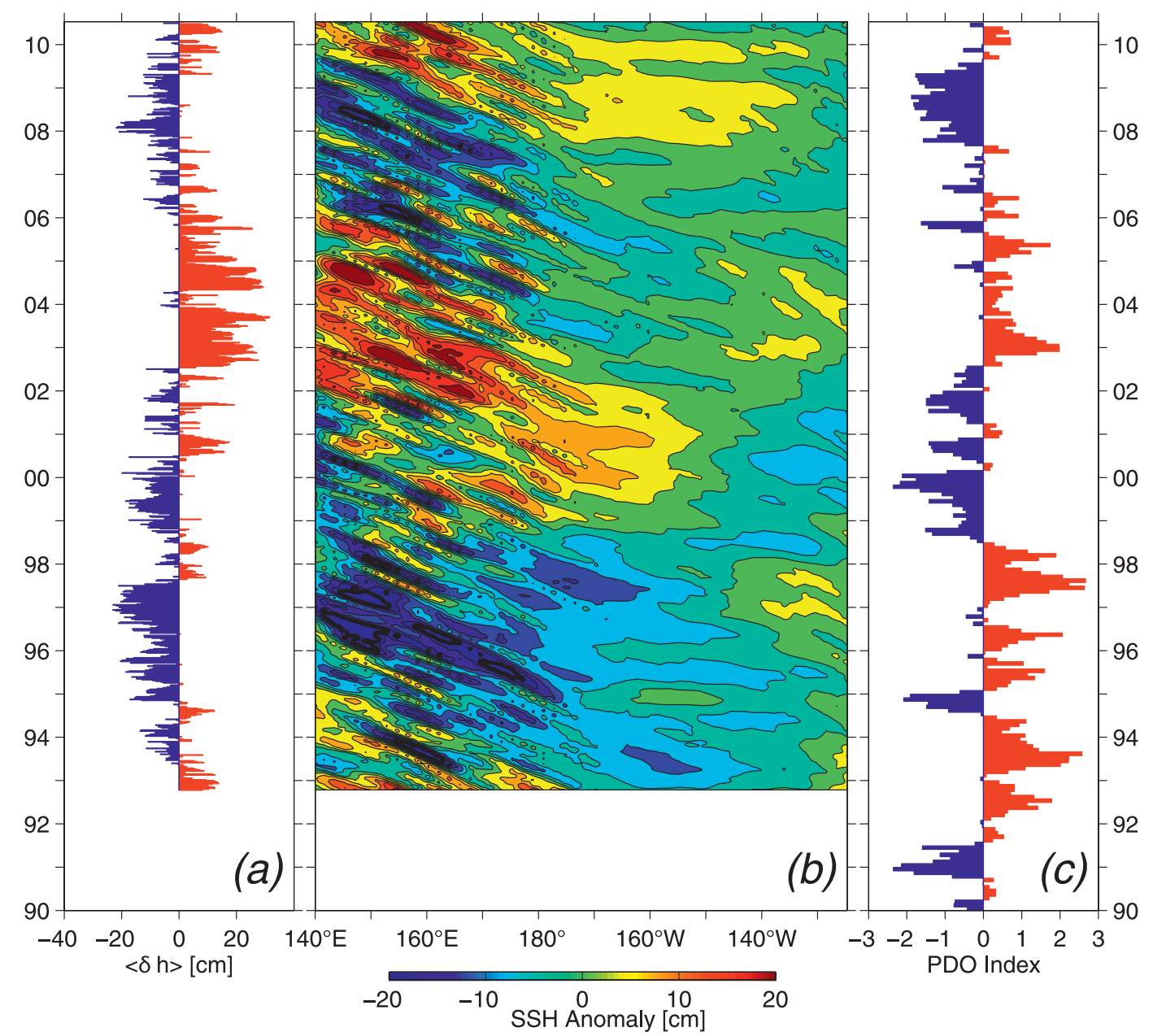

FIG. 5. (a) Time series of the SSH height difference across the KE jet averaged from $140^{\circ}$ to $165^{\circ} \mathrm{E}$; as in Fig. $3 \mathrm{c}$ but plotted as deviations from the time-mean value. (b) SSH anomalies along the zonal band $32^{\circ}-34^{\circ} \mathrm{N}$ from the satellite altimeter data. (c) PDO index from the Joint Institute for the Study of the Atmosphere and Ocean Web site (available online at http://jisao.washington.edu/pdo/PDO.latest).

Figure $6 c$ shows the mean depth of the 26.7-26.8 $\sigma_{\theta}$ surface determined from the in situ $T-S$ data. The depth varies from $200 \mathrm{~m}$ in the northern subarctic region to 700-750 $\mathrm{m}$ inside the $\mathrm{KE}$ recirculation gyre. This depth range corresponds to the lower part of the permanent thermocline in the North Pacific subtropical gyre. Notice that the depth distribution of Fig. $6 \mathrm{c}$ bears a good resemblance to the mean SSH pattern shown in Fig. 1.

Despite the accumulation of profiling float measurements in the past decade (Fig. 6a), the amount of the $T-S$ data in the region of our interest is still insufficient to explore the time-varying NPIW signals on an annual basis. To overcome this problem, we adopt a composite analysis approach in this study. Specifically, we seek to detect the NPIW property changes in the following two contrasting periods: 2002-05 versus 2006-09.
As shown in Fig. 3, the 2002-05 period corresponds to when both the KE jet and recirculation gyre were intensified and when the mesoscale eddy activity was reduced (enhanced) in the upstream (downstream) KE region. During 2006-09, the dynamic state of the $\mathrm{KE}$ is reversed. With each composite spanning four years, spatial data gaps are no longer an issue, and the data numbers in the two composites are approximately equal.

Figures $7 \mathrm{a}, \mathrm{b}$ show distributions of the salinity anomaly on the 26.7-26.8 $\sigma_{\theta}$ surface for 2002-05 and 2006-09, respectively. Here the salinity anomalies are defined as deviations from the mean salinity field shown in Fig. 6 b. The detected salinity anomalies have generally coherent spatial patterns. During 2002-05, positive salinity anomalies are detected along the inflow KE jet southeast of Japan and in the Mixed Water region east of $152^{\circ} \mathrm{E}$. In 
(a) Argo/CTD Salinity on 26.7-26.8 $\sigma_{\theta}: 36063$ Profiles

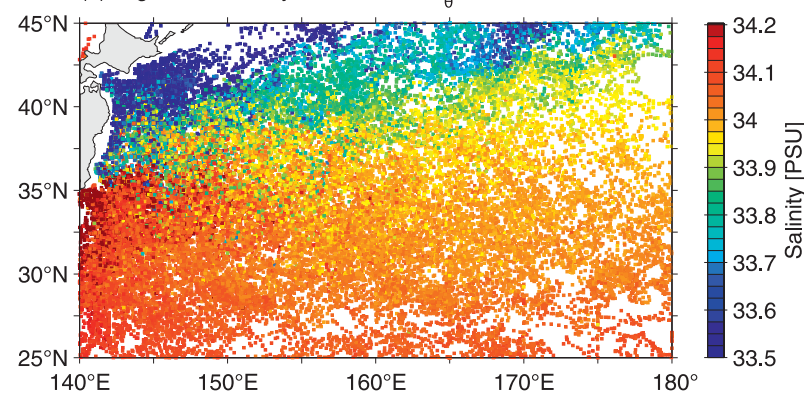

(b) Salinity on $26.7-26.8 \sigma_{\theta}$

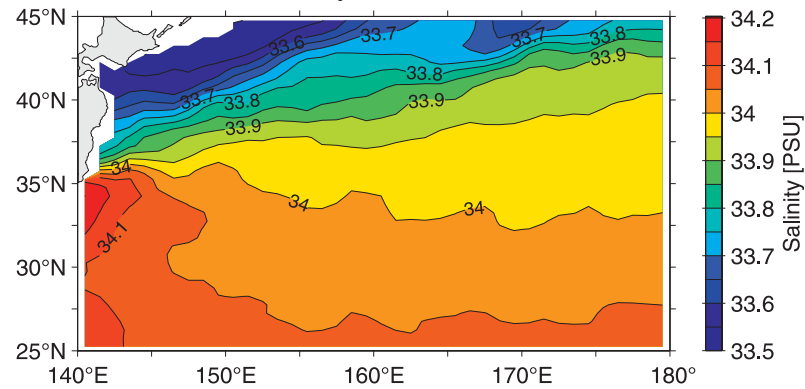

(c) Depth of $26.7-26.8 \sigma_{\theta}$

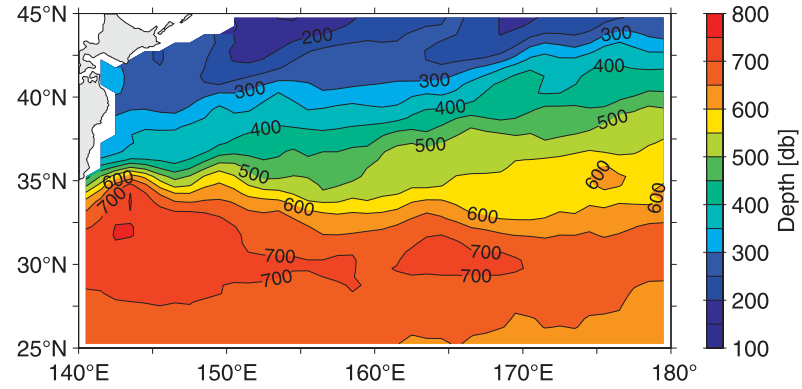

FIG. 6. Salinity values on the 26.7-26.8 $\sigma_{\theta}$ surface (a) from available profiling float and CTD measurements and (b) interpolated from the individual measurements. (c) Depth distribution of the 26.7-26.8 $\sigma_{\theta}$ surface.

contrast, negative salinity anomalies are observed in the western Mixed Water region and in the broad region south of the KE jet. The peak salinity anomalies have values at \pm 0.05 psu. During 2006-09, the salinity anomalies exhibit a pattern roughly opposite to that of 2002-05. In terms of the 26.7-26.8 $\sigma_{\theta}$ isopycnal depth, Fig. 7c shows that its anomalies are positive (i.e., deepening) to the south and negative to the north of the KE jet during 2002-05. This depth anomaly signifies the sharpening of the $\mathrm{KE}$ front and reflects the strengthening and elongation of the KE jet during 2002-05. Like the salinity anomalies, the depth anomalies in 2006-09 (Fig. 7d) show a spatial pattern opposite to that of 2002-05. In accordance with the results from SSH measurements, the $\mathrm{KE}$ jet in 2006-09 is weaker and zonally more contracted.

\section{Examining NPIW salinity changes with an isopycnal model}

To clarify the causes for the observed salinity changes shown in Figs. 7a,b, we adopt in this section a numerical modeling approach. We assume that, away from the low salinity water formation regions of Okhotsk Sea and along the Kuril Islands, the salinity values on the $26.7-26.8 \sigma_{\theta}$ surface in the broad open ocean regions of our interest are controlled predominantly by alongisopycnal advection and diffusion processes. By using the isopycnal advection-diffusion model, we seek to explore processes through which the decadally varying $\mathrm{KE}$ jet and its eddy field are able to alter the salinity signals of NPIW.

\section{a. Velocity specification on the 26.7-26.8 $\sigma_{\theta}$ surface}

Quantification of the NPIW salinity changes requires knowledge of the time-varying velocity field on the 26.7$26.8 \sigma_{\theta}$ surface. Although we have no directly measured velocity information on this isopycnal surface, the good resemblance between the isopycnal depth and the $\mathrm{SSH}$ field (cf. Figs. 1, 6c) suggests that a link may be sought between the SSH and acceleration potential signals on the 26.7-26.8 $\sigma_{\theta}$ surface. To do so, we calculate the acceleration potential values from all available $T-S$ profiles relative to the concurrently measured $\mathrm{SSH}$ values from satellite altimeters. Figure 8a shows the scatterplot between the acceleration potential values thus determined and the concurrent SSH values. The relatively tight correspondence between these two quantities makes it reasonable to derive the needed acceleration potential field $A(x, y, t)$ from the altimetrically measured SSH field $h(x, y, t)$

$$
A(x, y, t)=\alpha(h) h(x, y, t)
$$

where $\alpha(h)$ is the conversion coefficient determined by least-square fitting (i.e., the red curve shown in Fig. 8a). As an example, we plot in Fig. $8 \mathrm{~b}$ the mean acceleration potential field on the 26.7-26.8 $\sigma_{\theta}$ surface converted from the mean SSH field of Fig. 1 using Eq. (2). Once $A(x, y, t)$ is determined, the isopycnal velocity is simply

$$
(u, v)=\left(-\frac{1}{f} \frac{\partial A}{\partial y}, \frac{1}{f} \frac{\partial A}{\partial x}\right) .
$$

\section{b. Isopycnal advection-diffusion model and control run}

The equation governing the salinity $S$ changes along an isopycnal surface is 
(a) S Anomaly: 2002-05

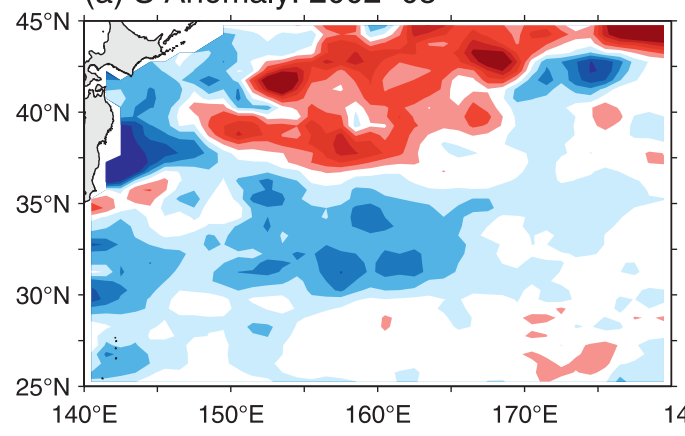

(c) Depth Anomaly: 2002-05

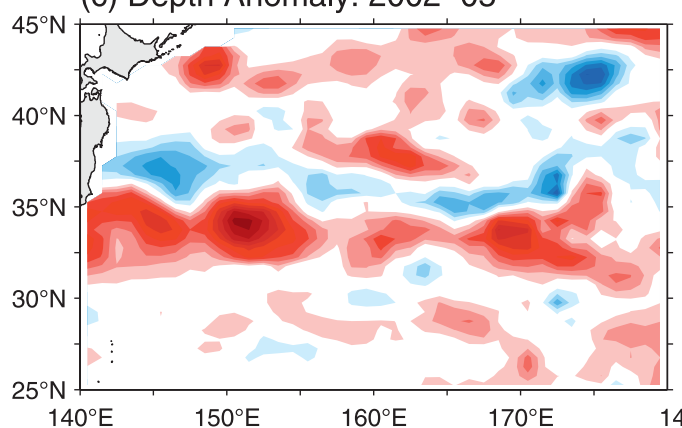

(b) S Anomaly: 2006-09

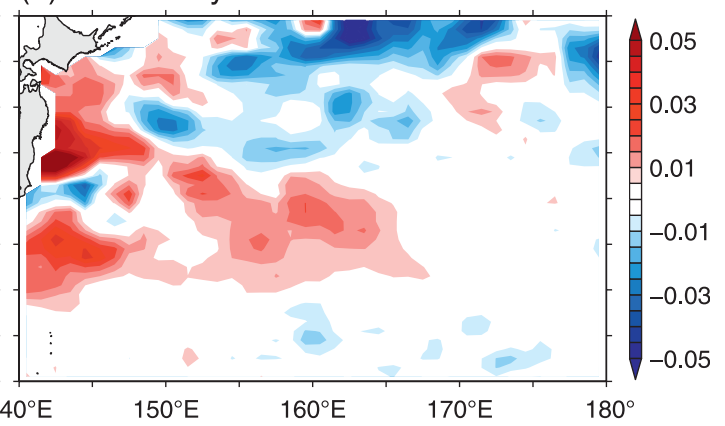

(d) Depth Anomaly: 2006-09

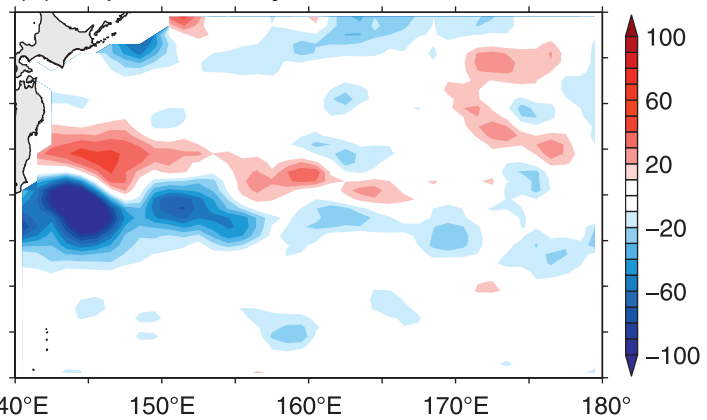

FIG. 7. Salinity anomaly distributions on the 26.7-26.8 $\sigma_{\theta}$ surface in (a) 2002-05 and (b) 2006-09. Depth anomaly distributions of the 26.7-26.8 $\sigma_{\theta}$ surface in (c) 2002-05 and (d) 2006-09. Salinity and depth anomalies are relative to the mean distributions shown in Figs. 6b,c, respectively.

$$
\frac{\partial S}{\partial t}+u \frac{\partial S}{\partial x}+v \frac{\partial S}{\partial y}=K_{i}\left(\frac{\partial^{2} S}{\partial x^{2}}+\frac{\partial^{2} S}{\partial y^{2}}\right)
$$

where $(u, v)$ are given by Eq. (3) and $K_{i}$ is the isopycnal eddy diffusivity. As we noted above, effects of diapycnal processes are assumed to be small in the region of our interest and excluded from Eq. (4). We solve Eq. (4) numerically with the use of an upwind scheme (e.g., Kantha and Clayson 2000). The model has a horizontal grid resolution of $1 / 3^{\circ} \times 1 / 3^{\circ}$ and its domain is chosen the same as that for the data analysis: $25^{\circ}-45^{\circ} \mathrm{N}, 140^{\circ} \mathrm{E}-180^{\circ}$. Although it is desirable to specify the salinity values from observations along the model boundaries, lack of continuous observations prevents us from doing so. Instead, we fix the $S$ values along the model boundaries with the observed mean salinity values (i.e., those shown in Fig. 6b). With this fixed boundary condition, changes in the modeled salinity field should be interpreted as solely due to the time-varying advective field and the specified $K_{i}$ value. All model runs described below are initiated with a uniform salinity at 34.0 psu. As it takes about $2 \mathrm{yr}$ for the modeled salinity field to reach the quasi-equilibrium state, model results from the initial $3 \mathrm{yr}$ are excluded from the analysis.

For the main model run conducted in this study (referred to as the control run below), we integrate Eq. (4) forward from October 1992 to June 2010 with $u$ and $v$ converted from the weekly, altimeter-derived SSH data. With the SSH field explicitly resolving the mesoscale eddy signals (Le Traon and Dibarboure 1999), we set the isopycnal eddy diffusivity $K_{i}=0$ in this control run. Figure 9a shows the modeled salinity distribution averaged between 2002 and 2009 from the control run. The overall pattern compares favorably with the observed mean salinity pattern of the same period shown in Fig. 6 b. The rms difference between the two mean salinity fields is 0.03 psu. Notice that including additional parameterized eddy diffusion in Eq. (4), that is, $K_{i} \neq 0$, does not quantitatively improve the match between the modeled and observed mean salinity patterns (figure not shown).

Figures 9b,c shows the modeled salinity anomaly patterns averaged in 2002-05 versus 2006-09 from the control run. Compared to the observed salinity anomaly pattern of 2002-05, Fig. $9 \mathrm{~b}$ reveals that the model is able to reproduce most of the salient observed features, including the localized high salinity anomalies in the inflow KE jet, the low salinity anomalies to the east of Japan, the high salinity anomalies within the broad Mixed Water region, and the low salinity anomalies occupying south of the KE jet along approximately $35^{\circ} \mathrm{N}$. One noticeable difference between Figs. $9 b$ and $7 a$ is seen to the east of $165^{\circ} \mathrm{E}$ where the modeled low salinity anomalies 

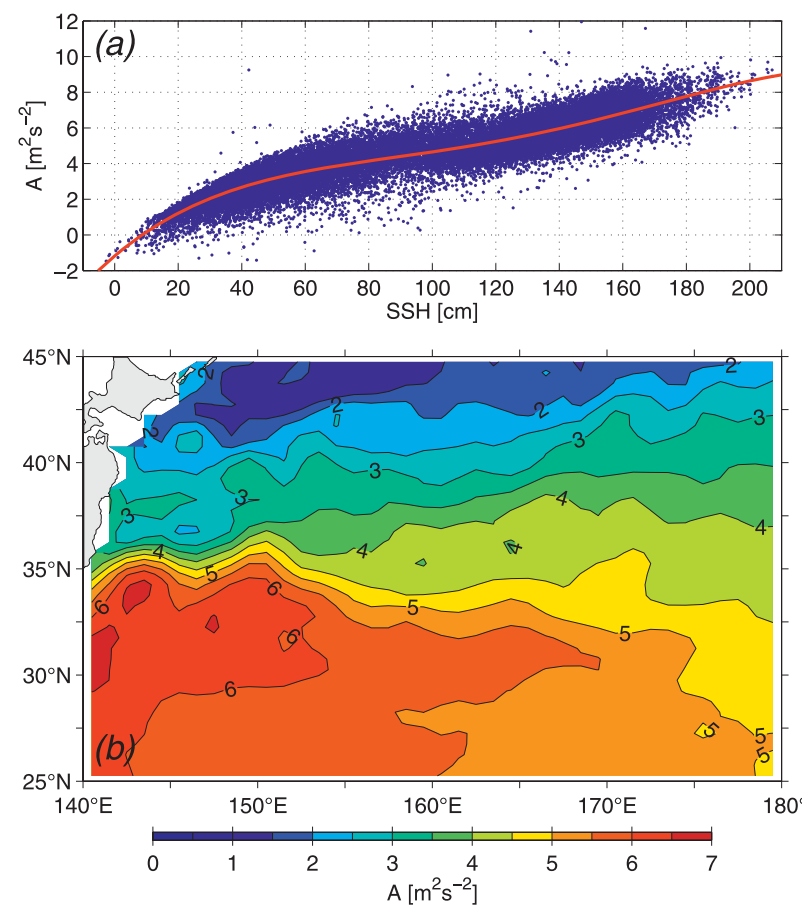

FIG. 8. (a) Scatterplot of acceleration potential values on the 26.7-26.8 $\sigma_{\theta}$ surface from individual $T-S$ profiles vs the collocated $\mathrm{SSH}$ values from altimeter measurements. The acceleration potential value is referenced to the sea surface. (b) Mean acceleration potential field on 26.7-26.8 $\sigma_{\theta}$ inferred from the mean SSH data using the conversion (i.e., the red curve) shown in (a).

south of the KE jet appear to be more prominent than the observations.

\section{c. Low-frequency KE jet versus mesoscale eddy variabilities}

Changes in the salinity field shown in Figs. 9b,c are caused by the flow variability on various time scales. To clarify the roles played by the circulations with different time scales, we decompose the acceleration potential value on the $26.7-26.8 \sigma_{\theta}$ surface into the following three components:

$$
A(x, y, t)=\bar{A}(x, y)+\widetilde{A}(x, y, t)+A^{\prime}(x, y, t),
$$

where $\bar{A}$ denotes the time-mean acceleration potential field given in Fig. 8. The time-dependent $A$ field is divided into the low-pass and high-pass filtered components, $\widetilde{A}$ and $A^{\prime}$, where the dividing period is set at $7 \mathrm{yr}$. Thus divided, $\widetilde{A}$ represents signals of the decadally modulating KE jet/recirculation gyre, and $A^{\prime}$ represents the remaining, spatially and temporally varying, mesoscale eddy signals (recall Figs. 3a,b).

It is instructive to first examine the model run in which the acceleration potential field is given by $A=\bar{A}+\widetilde{A}$. (a) Mean S Field: Control Run

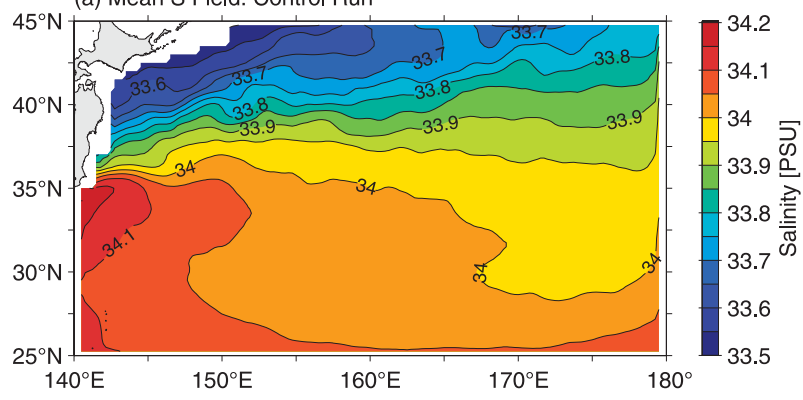

(b) S Anomaly: 2002-05

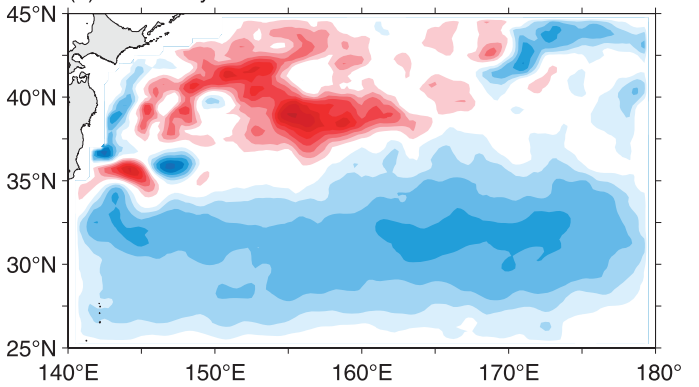

(c) S Anomaly: 2006-09

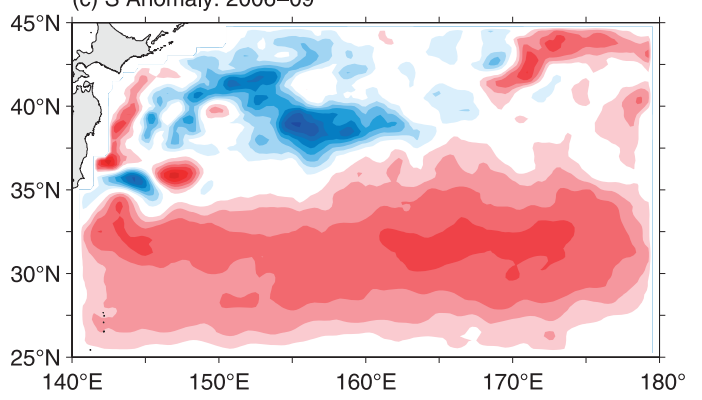

FIG. 9. (a) Mean salinity field on the 26.7-26.8 $\sigma_{\theta}$ surface for 2002-09 from the control model run. Modeled salinity anomaly field for (b) 2002-05 vs (c) 2006-09.

In other words, the advective field contains no mesoscale eddy signals in this "eddy free" run (see Table 1 for the different model run specifications). As may be expected, the modeled mean salinity field for 2002-09 from this run (Fig. 10a) becomes too saline in the subtropical region south of $\sim 38^{\circ} \mathrm{N}$ and too fresh north of $\sim 38^{\circ} \mathrm{N}$

TABLE 1. Specifications of acceleration potential and isopycnal eddy diffusivity values in Eq. (4) for different model runs.

\begin{tabular}{lcc}
\hline \hline \multicolumn{1}{c}{ Model } & $\begin{array}{c}\text { Acceleration } \\
\text { potential field }\end{array}$ & $\begin{array}{c}K_{i} \text { value } \\
\left(\mathrm{m}^{2} \mathrm{~s}^{-1}\right)\end{array}$ \\
\hline $\begin{array}{l}\text { Control run } \\
\text { Eddy-free run } \\
\begin{array}{l}\text { Parameterized eddy } \\
\text { diffusion run }\end{array}\end{array}$ & $\bar{A}+\widetilde{A}+A^{\prime}$ & 0 \\
$\begin{array}{c}\text { Modulating eddy } \\
\text { forcing run }\end{array}$ & $\bar{A}+\widetilde{A}$ & 0 \\
\hline
\end{tabular}


(a) Mean S Field: Eddy-Free Run

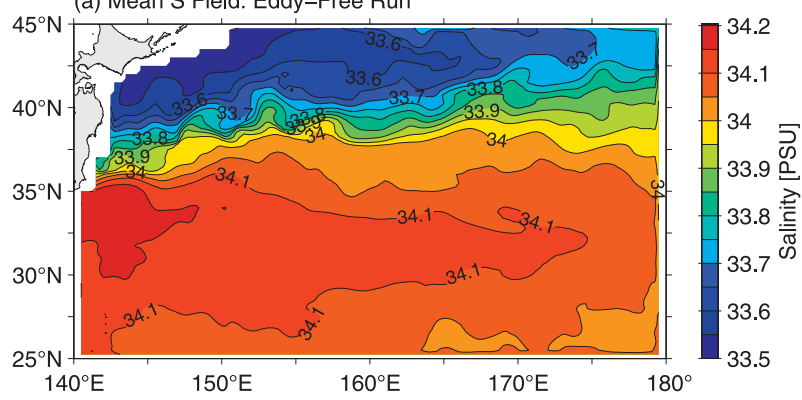

(b) S Anomaly: 2002-05

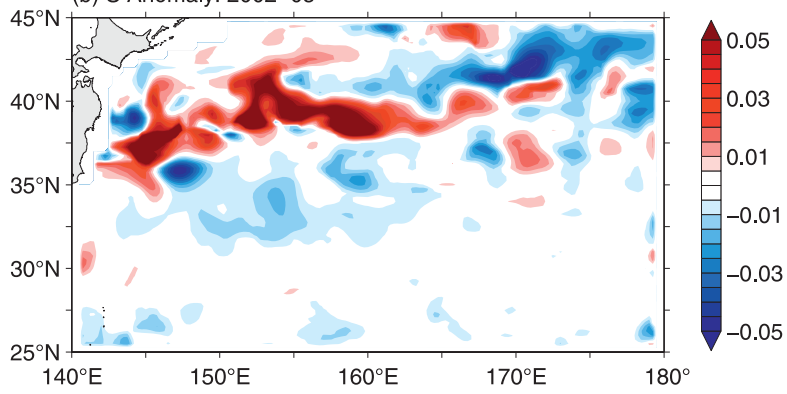

FIG. 10. As in Figs. 9a,b but for the eddy-free run. See Table 1 for the model specifications. The modeled salinity anomaly field in 2006-09 has a pattern opposite to (b) and is thus not shown.

when compared to the control run result. For the modeled time-varying salinity signals in 2002-05, Fig. 10b shows that a band of positive salinity anomalies extends northeastward along $36^{\circ}-40^{\circ} \mathrm{N}$. Presence of this positive salinity anomaly band is due to the intensified and northerly located KE jet during the period of 2002-05 (Figs. 3c,d). Negative salinity anomalies, on the other hand, are seen in the $33^{\circ}-37^{\circ} \mathrm{N}$ band, in Fig. $10 \mathrm{~b}$, from $145^{\circ} \mathrm{E}$ to the date line, and their existence is due to the southward migration of the weakened KE jet during 2006-09 (recall that the salinity anomalies shown in Fig. $10 \mathrm{~b}$ are relative to the $2002-09$ mean salinity distribution).

To explore the roles of mesoscale eddy signals, we extend the above eddy-free model run by incorporating the effect of isopycnal eddy diffusion in Eq. (4). The eddy diffusivity for this "parameterized eddy diffusion run," $K_{i}=4000 \mathrm{~m}^{2} \mathrm{~s}^{-1}$, is chosen such that the modeled mean salinity pattern for 2002-09 (Fig. 11a) approaches the observed mean salinity pattern presented in Fig. 6 b. The salinity anomaly pattern for 2002-05 from this model run is shown in Fig. 11b. Reflecting the incorporation of spatially uniform eddy diffusion, Fig. 11b shows a laterally "diffused" salinity anomaly pattern when compared to the eddy-free run result of Fig. 10b. It is worth noting that this diffused salinity anomaly pattern bears some resemblance to Fig. 7a, indicating that the decadally fluctuating $\mathrm{KE}$ jet plays an important role in generating (a) Mean S Field: Parameterized Eddy Diffusion Run

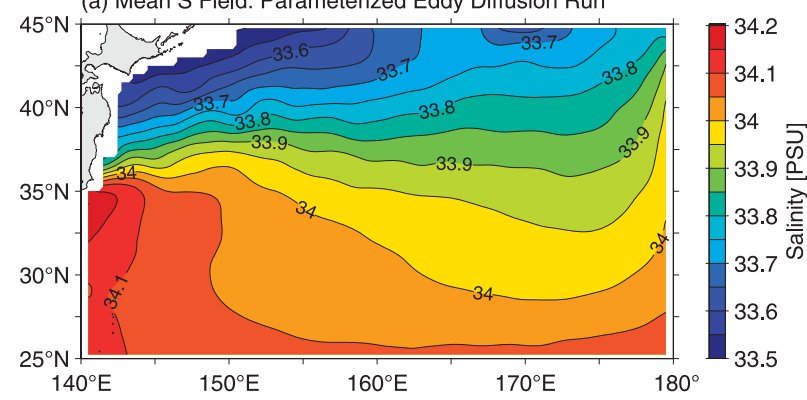

(b) S Anomaly: 2002-05

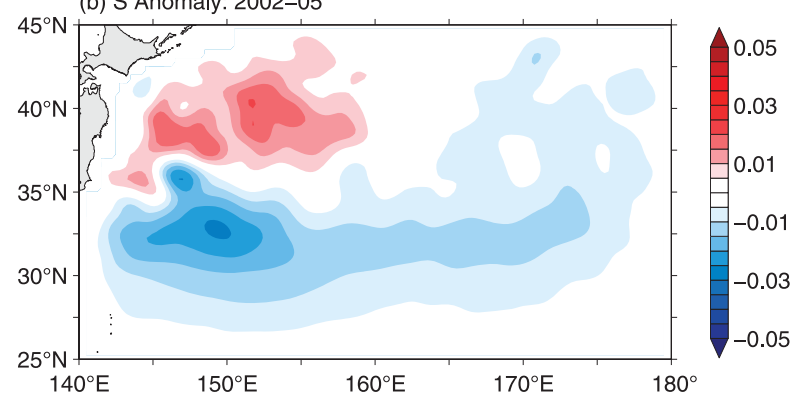

FIG. 11. As in Fig. 10 but for the parameterized eddy diffusion run.

the broad-scale, dipolar salinity anomaly pattern detected in the observations.

In the above parameterized eddy diffusion run, effects of mesoscale eddies were assumed to be uniform both spatially and temporally. As analyzed in section 2, the observed mesoscale eddy signals in the region of our interest are neither uniform in space nor time. To assess the roles played by the decadally modulating eddy forcing, we conduct a fourth model run in which we set $A=\bar{A}+A^{\prime}$ and $K_{i}=0$. For this "modulating eddy forcing run" the advective field is fully specified by the observations, except for the decadally varying circulation signals. The mean salinity field for 2002-09 from this model run (Fig. 12a) exhibits a pattern very similar to the observations and the control run (cf. Fig. 9a), suggesting dominance of the eddy contribution in determining the time-mean salinity pattern in the region of our interest.

The observed eddy forcing generates salinity anomalies that are large in amplitude and, when combined with the forced signals from the decadally varying $\mathrm{KE}$ jet, match better the observed salinity anomaly pattern. Specifically, in the downstream KE region east of $152^{\circ} \mathrm{E}$, the observed eddy forcing in 2002-05 induces a positive (negative) salinity anomaly to the north (south) of the KE jet (see Fig. 12b). This eddy-induced dipolar salinity anomaly reinforces/expands the dipolar salinity anomaly pattern generated by the decadally varying $\mathrm{KE}$ jet farther to the east (cf. Fig. 11b), making the combined salinity anomaly pattern closer to the observations. 
(a) Mean S Field: Modulating Eddy Forcing Run

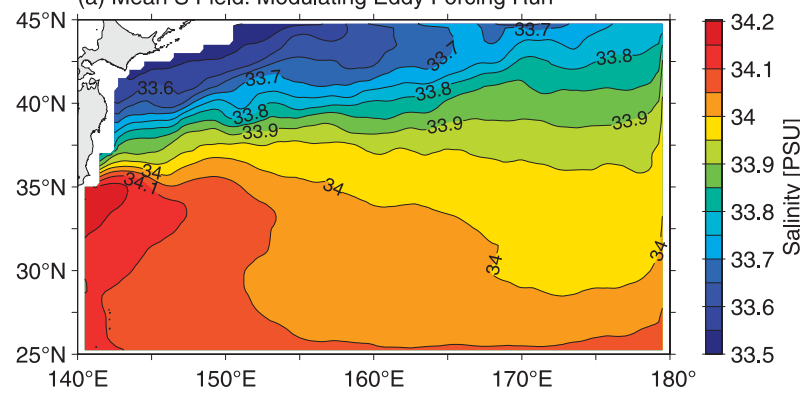

(b) S Anomaly: 2002-05

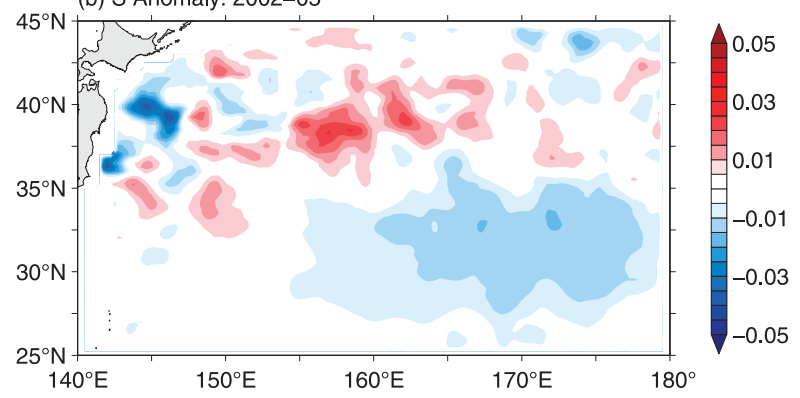

FIG. 12. As in Fig. 10 but for the modulating eddy forcing run.

Dynamically, the dipolar salinity anomaly pattern, shown in Fig. 12b, is due to the enhanced eddy variability in 2002-05 in the downstream KE region that transports saltier subtropical water northward and fresher subarctic water southward (recall Fig. 3b).

In the upstream $\mathrm{KE}$ region west of $152^{\circ} \mathrm{E}, 2002-05$ is the period when the regional eddy activity was reduced. As a result of this reduced eddy activity, fewer intrusions of the KE water occur in the Mixed Water region, and this is reflected in Fig. 12b by the presence of a negative salinity anomaly to the east of Japan. This negative salinity anomaly is clearly captured in the observations (Fig. 7a), and our modeling results indicate that its existence is not due to the decadally varying KE jet but is a consequence of its decadally modulating eddy activities.

\section{d. Decadal modulations versus linear trends}

With the salinity anomaly patterns presented in Figs. $7 \mathrm{a}, \mathrm{b}$, it is of interest to ask whether these observed signals represent linear trends in the changing salinity field. To address this question, we plot in Fig. 13a the modeled salinity anomaly field for 1996-2001 from the control model run. As shown in Fig. 3, the KE jet during that period was in a unstable and contracted dynamic state similar to 2006-09. Compared with the model result for 2006-09 (Fig. 9c), Fig. 13a shows a similar, broad-scale, dipolar salinity anomaly pattern, negative salinity anomalies along the inflow KE jet, and localized positive salinity anomalies east of Japan. These similarities indicate that it is the dynamical state of the KE system that

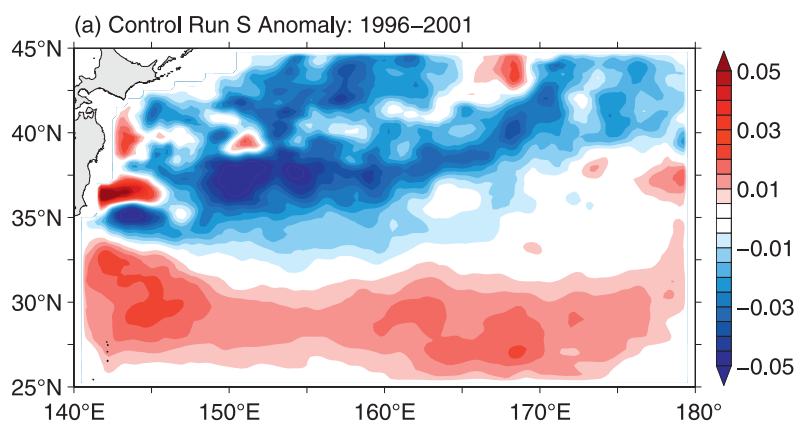

(b) Control Run S Anomaly as a Function of y-t: $152-165^{\circ} \mathrm{E}$

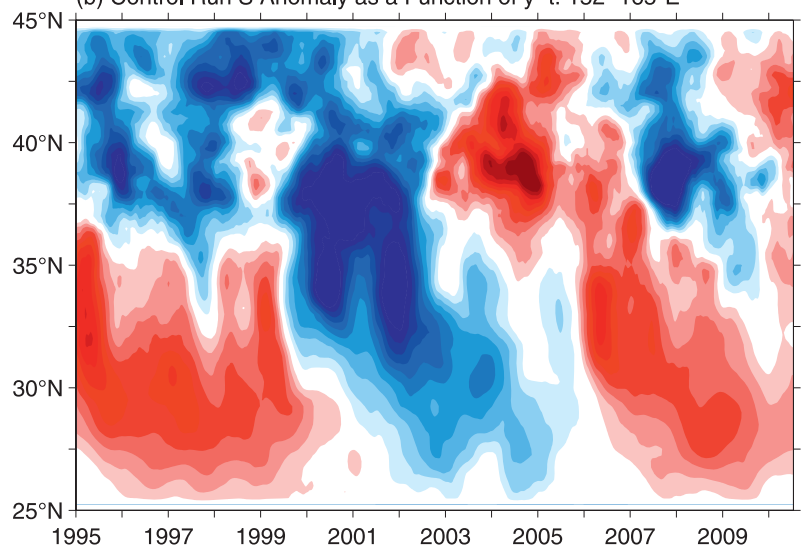

FIG. 13. (a) Salinity anomaly field for 1996-2001 from the control model run. (b) Salinity anomaly values in $152^{\circ}-165^{\circ} \mathrm{E}$ as a function of time and latitude from the control model run. Salinity anomalies in (a),(b) are relative to the model's 2002-09 mean values.

determines the observed time-varying signals shown in Fig. 7.

That the modeled salinity changes are results of decadal modulations, instead of linear trends, can also be readily confirmed in Fig. 13b in which we plot the salinity anomalies in the downstream $\mathrm{KE}$ region $\left(152^{\circ}-165^{\circ} \mathrm{E}\right)$ as a function of time and latitude from the control run. Notice that south of the KE jet, around $35^{\circ} \mathrm{N}$, the modeled salinity anomalies have a tendency to spread southward as time progresses. This spreading reflects the fact that the decadal salinity changes originate in the KE jet and that the induced salinity anomalies are subsequently permeated laterally by mesoscale eddies. The delayed spreading is less obvious in Fig. 13b north of the KE jet; this is because salinity signals in the Mixed Water region are affected not only by the time-varying KE jet from the south but also by the variability of the Oyashio and Subarctic Current from the north.

\section{Summary}

Using the temperature and salinity data from the International Argo and Kuroshio Extension System Study 
profiling floats and other in situ hydrographic measurements, we investigated in this study the property modifications of North Pacific Intermediate Water (NPIW) in the western North Pacific Ocean. Over the past eight years with sufficient $T-S$ data collected, we found that the salinity signals in the NPIW core layer of 26.7-26.8 $\sigma_{\theta}$ vary in concert with the decadal changes of the Kuroshio Extension's dynamical state. Specifically, during 2002-05 when the KE jet was intense and zonally elongated, coherent positive salinity anomalies appeared along the inflow KE jet southeast of Japan and in the downstream Mixed Water region east of $152^{\circ} \mathrm{E}$. Broad-scale negative salinity anomalies, on the other hand, were detected south of the KE jet and in the upstream Mixed Water region. The signs of these observed salinity anomalies were reversed in 2006-09 when the KE jet transitioned to a weakened and zonally contracted dynamic state.

To elucidate the processes responsible for these observed salinity changes, we adopted in this study an isopycnal advection-diffusion model and conducted process-oriented model runs by adjusting the timedependent advective field and isopycnal eddy diffusivity. For the salinity anomaly features observed in 2002-05, the model results indicate that, as the KE jet strengthened during this period, enhanced advection of saltier $\mathrm{KE}$ water caused the increased salinity value along the inflow KE jet southeast of Japan. The broad-scale dipolar salinity anomaly pattern with positive (negative) salinity anomalies appearing to the north (south) of the $\mathrm{KE}$ jet, on the other hand, is due to the combined effect of the northward migration of the KE jet and enhanced mesoscale eddy activities in the downstream KE region. Both of these processes result in a net northward salt flux, and the observed broad-scale dipolar salinity anomaly pattern is a manifestation of this net salt flux. In the upstream KE region west of $152^{\circ} \mathrm{E}$, mesoscale eddy activity was low in 2002-05, and this reduced eddy activity suppressed the northward transport of saline KE water and is responsible for the negative salinity anomalies detected in the western Mixed Water region.

Through the numerical model integrations, we identified that, rather than linear trends, the observed salinity anomalies in the past eight years are oscillatory in nature and are consequences of the decadally varying $\mathrm{KE}$ jet and its associated mesoscale eddies. One aspect that we are unable to address in our present study is the extent to which any of the observed salinity changes in the NPIW core layer are due to changes of salinity itself along the model's inflow boundaries. This "boundary effect" is expected to be small for the inflow KE jet south of Japan because the salinity value there is determined by the "old" intermediate water recirculated through the North Pacific subtropical gyre and is unlikely to change significantly on the decadal time scale of our interest. In contrast, the 26.7-26.8 $\sigma_{\theta}$ surface along the model's northern boundary is shallow ( $<200 \mathrm{~m}$ on average, see Fig. 6c) and the salinity values there are likely to be influenced by surface evaporation minus precipitation $(\mathrm{E}-\mathrm{P})$ forcing and input of waters ventilated in the Okhotsk Sea and the western subarctic gyre. With the launch of the Aquarius/Satelite de Aplicaciones Cientificas-D (SAC-D) satellite measuring sea surface salinity scheduled for 2011 (Lagerloef et al. 2008), it would be interesting for future data analysis and modeling studies to quantify the contribution to the NPIW modification from these near-surface processes in the northern subarctic region.

Acknowledgments. The Argo profiling float data used in this study were provided by the US-GODAE Argo Global Data Assembly Center, the supplementary CTD data from the JODC and KESS Web sites, and the merged T/P, Jason-1, and ERS-1/2 altimeter data by the CLS Space Oceanography Division as part of the Environment and Climate EU ENACT project. This study was supported by NSF through Grant OCE-0220680 and NASA through Contract 1207881 as part of NASA's Ocean Surface Topography Mission.

\section{REFERENCES}

Berloff, P., A. M. Hogg, and W. K. Dewar, 2007: The turbulent oscillator: A mechanism of low-frequency variability of the wind-driven ocean gyres. J. Phys. Oceanogr., 37, 2362-2386.

Ceballos, L., E. Di Lorenzo, C. D. Hoyos, N. Schneider, and B. Taguchi, 2009: North Pacific gyre oscillation synchronizes climate variability in the eastern and western boundary current systems. J. Climate, 22, 5163-5174.

Deser, C., M. A. Alexander, and M. S. Timlin, 1999: Evidence for a wind-driven intensification of the Kuroshio Current Extension from the 1970 s to the 1980 s. J. Climate, 12, 16971706.

Ducet, N., P.-Y. Le Traon, and G. Reverdin, 2000: Global highresolution mapping of ocean circulation from TOPEX/Poseidon and ERS-1 and -2. J. Geophys. Res., 105, 19 477-19 498.

Kantha, L. H., and C. A. Clayson, 2000: Numerical Models of Oceans and Oceanic Processes. Academic Press, 940 pp.

Kelly, K. A., L. Thompson, W. Cheng, and E. J. Metzger, 2007: Evaluation of HYCOM in the Kuroshio Extension region using new metrics. J. Geophys. Res., 112, C01004, doi:10.1029/ 2006JC003614.

Kouketsu, S., I. Kaneko, T. Kawano, H. Uchida, T. Doi, and M. Fukasawa, 2007: Changes of North Pacific Intermediate Water properties in the subtropical gyre. Geophys. Res. Lett., 34, L02605, doi:10.1029/2006GL028499.

Lagerloef, G., and Coauthors, 2008: The Aquarius/SAC-D mission: Designed to meet the salinity remote-sensing challenge. Oceanography, 21, 68-81.

Le Traon, P.-Y., and G. Dibarboure, 1999: Mesoscale mapping capabilities of multiple-satellite altimeter missions. J. Atmos. Oceanic Technol., 16, 1208-1223. 
Mantua, N. J., S. R. Hare, Y. Zhang, J. M. Wallace, and R. C. Francis, 1997: A Pacific interdecadal climate oscillation with impacts on salmon production. Bull. Amer. Meteor. Soc., 78, 1069-1079.

Miller, A. J., D. R. Cayan, and W. B. White, 1998: A westwardintensified decadal change in the North Pacific thermocline and gyre-scale circulation. J. Climate, 11, 3112-3127.

Mizuno, K., and W. B. White, 1983: Annual and interannual variability in the Kuroshio Current system. J. Phys. Oceanogr., 13, 1847-1867.

Nakano, H., and I. Ishikawa, 2010: Meridional shift of the Kuroshio Extension induced by response of recirculation gyre to decadal wind variations. Deep-Sea Res. II, 57, 1111-1126.

Oka, E., 2009: Seasonal and interannual variation of North Pacific Subtropical Mode Water in 2003-2006. J. Oceanogr., 65, 151-164.

_ , T. Suga, C. Sukigara, K. Toyama, K. Shimada, and J. Yoshida, 2011: "Eddy resolving" observation of the North Pacific Subtropical Mode Water. J. Phys. Oceanogr., in press.

Pierini, S., H. A. Dijkstra, and A. Riccio, 2009: A nonlinear theory of the Kuroshio Extension bimodality. J. Phys. Oceanogr., 39, 2212-2229.

Qiu, B., 1995: Why is the North Pacific Intermediate Water confined on density surfaces around $\sigma_{\theta}=26.8$ ? J. Phys. Oceanogr. 33, 2465-2482.

_ 2003: Kuroshio Extension variability and forcing of the Pacific decadal oscillations: Responses and potential feedback. J. Phys. Oceanogr., 33, 2465-2482.

_ , and S. Chen, 2005: Variability of the Kuroshio Extension jet, recirculation gyre and mesoscale eddies on decadal timescales. J. Phys. Oceanogr., 35, 2090-2103.

— , and _ 2006: Decadal variability in the formation of the North Pacific Subtropical Mode Water: Oceanic versus atmospheric control. J. Phys. Oceanogr., 36, 1365-1380.

— , and — 2010: Eddy-mean flow interaction in the decadally modulating Kuroshio Extension system. Deep-Sea Res. II, 57, 1098-1110.

_ K. A. Kelly, and T. M. Joyce, 1991: Mean flow and variability in the Kuroshio Extension from Geosat altimetry data. J. Geophys. Res., 96, 18 491-18 507.

_ S. Chen, and P. Hacker, 2007: Effect of mesoscale eddies on Subtropical Mode Water variability from the Kuroshio Extension System Study (KESS). J. Phys. Oceanogr., 37, 9821000.

Reid, J. L., 1965: Intermediate Water of the Pacific Ocean. Johns Hopkins Oceanographic Studies. Vol. 2, The John Hopkins Press, $58 \mathrm{pp}$.

Rio, M.-H., P. Schaeffer, G. Moreaux, J.-M. Lemoine, and E. Bronner, 2009: A new mean dynamic topography computed over the global ocean from GRACE data, altimetry and in-situ measurements. Proc. OceanObs09 Symp., Venice, Italy.
[Available online at http://www.aviso.oceanobs.com/fileadmin/ documents/data/products/auxiliary/MDT_Cnes-CLS09_poster_ Oceanobs09.pdf.]

Roemmich, D., and Coauthors, 2009: The Argo program: Observing the global ocean with profiling floats. Oceanography, 22, 34-43.

Seager, R., Y. Kushnir, N. H. Naik, M. A. Cane, and J. Miller, 2001: Wind-driven shifts in the latitude of the Kuroshio-Oyashio extension and generation of SST anomalies on decadal timescales. J. Climate, 14, 4249-4265.

Smith, W. H. F., and D. T. Sandwell, 1994: Bathymetric prediction from dense altimetry and sparse shipboard bathymetry. J. Geophys. Res., 99, 21 803-21 824.

Sugimoto, S., and K. Hanawa, 2010: Impact of Aleutian Low activity on the STMW formation in the Kuroshio recirculation gyre region. Geophys. Res. Lett., 37, L03606, doi:10.1029/ 2009GL041795.

Taguchi, B., S.-P. Xie, H. Mitsudera, and A. Kubokawa, 2005: Response of the Kuroshio Extension to Rossby waves associated with the 1970s climate shift in a high-resolution ocean model. J. Climate, 18, 2979-2995.

,$\ldots$, N. Schneider, M. Nonaka, H. Sasaki, and Y. Sasai, 2007: Decadal variability of the Kuroshio Extension: Observations and an eddy-resolving model hindcast. J. Climate, 20, 2357-2377.

Talley, L. D., 1991: An Okhotsk Sea water anomaly: Implication for ventilation in the North Pacific. Deep-Sea Res., 38, S171S190.

- 1993: Distribution and formation of North Pacific Intermediate Water. J. Phys. Oceanogr., 23, 517-537.

1997: North Pacific Intermediate Water transports in the Mixed Water region. J. Phys. Oceanogr., 27, 1795-1803.

Van Scoy, K., D. B. Olson, and R. A. Fine, 1991: Ventilation of North Pacific Intermediate Water: The role of the Alaskan gyre. J. Geophys. Res., 96, 16 801-16 810.

Yasuda, I., 1997: The origin of the North Pacific Intermediate Water. J. Geophys. Res., 102, 893-909.

, 2004: North Pacific Intermediate Water: Progress in SAGE (SubArctic Gyre Experiment) and related projects. J. Oceanogr., 60, 385-395.

- K. Okuda, and M. Hirai, 1992: Evolution of a Kuroshio warm-core ring-Variability of the hydrographic structure. Deep-Sea Res., 39, 131-161.

, and Y. Shimizu, 1996: Distribution and modification of North Pacific Intermediate Water in the Kuroshio-Oyashio interfrontal zone. J. Phys. Oceanogr., 26, 448-465.

You, Y., N. Suginohara, M. Fukasawa, I. Yasuda, I. Kaneko, H. Yoritaka, and M. Kawamiya, 2000: Roles of the Okhotsk Sea and Gulf of Alaska in forming the North Pacific Intermediate Water. J. Geophys. Res., 105, 3253-3280. 